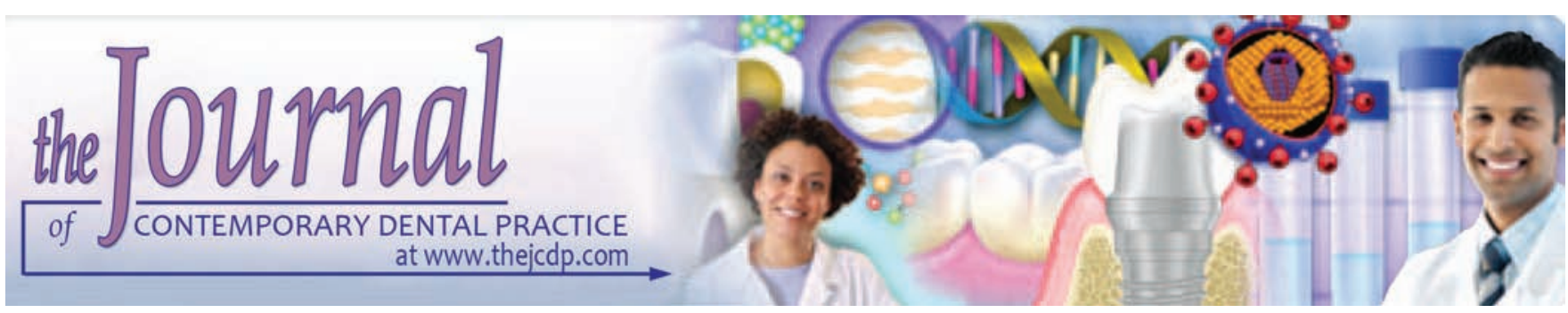

\title{
An Accurate Methodology to detect Leaching of Nickel and Chromium Ions in the Initial Phase of Orthodontic Treatment: An in vivo Study
}

${ }^{1} \mathrm{R}$ Vinoth Kumar, ${ }^{2} \mathrm{~N}$ Rajvikram, ${ }^{3} \mathrm{P}$ Rajakumar, ${ }^{4} \mathrm{R}$ Saravanan, ${ }^{5} \mathrm{~V}$ Arun Deepak, ${ }^{6} \mathrm{~V}$ Vijaykumar

\begin{abstract}
Aim: The aim of this study was to evaluate the release of nickel and chromium ions in human saliva during fixed orthodontic therapy.

Materials and methods: Ten patients with Angle's Class-I malocclusion with bimaxillary protrusion without any metal restorations or crowns and with all the permanent teeth were selected. Five male patients and five female patients in the age group range of 14 to 23 years were scheduled for orthodontic treatment with first premolar extraction. Saliva samples were collected in three stages: sample 1, before orthodontic treatment; sample 2, after 10 days of bonding sample; and sample 3, after 1 month of bonding. The samples were analyzed for the following metals nickel and chromium using inductively coupled plasma optical emission spectrometry (ICP-OES).
\end{abstract}

Results: The levels of nickel and chromium were statistically significant, while nickel showed a gradual increase in the first 10 days and a decline thereafter. Chromium showed a gradual increase and was statistically significant on the 30th day.

Conclusion: There was greatest release of ions during the first 10 days and a gradual decline thereafter. Control group had traces of nickel and chromium. While comparing levels of nickel in saliva, there was a significant rise from baseline to 10th and 30th-day sample, which was statistically significant. While comparing 10th day to that of 30th day, there was no statistical significance. The levels of chromium ion in the saliva were more in 30th day, and when comparing 10th-day sample with 30th day, there was statistical significance.

Clinical significance: Nickel and chromium levels were well within the permissible levels. However, some hypersensitive individuals may be allergic to this minimal permissible level.

\footnotetext{
${ }^{1-6}$ Department of Orthodontics, Thai Moogambigai Dental College and Hospital, Chennai, Tamil Nadu, India
}

Corresponding Author: P Rajakumar, Reader, Department of Orthodontics, Thai Moogambigai Dental College and Hospital, Chennai-600107, Tamil Nadu, India, Phone: 9444466148, e-mail: rajscare@hotmail.com
Keywords: Chromium, Inductively Coupled Plasma Optical Emission Spectrometry (ICP-OES), Nickel, Saliva.

How to cite this article: Kumar RV, Rajvikram N, Rajakumar $\mathrm{P}$ Saravanan R, Deepak VA, Vijaykumar V. An Accurate Methodology to detect Leaching of Nickel and Chromium Ions in the Initial Phase of Orthodontic Treatment: An in vivo Study. J Contemp Dent Pract 2016;17(3):205-210.

Source of support: Nil

Conflict of interest: None

\section{INTRODUCTION}

Orthodontic materials must have specific characteristics, such as biological safety and functionality, adequate tissue response, and resistance to corrosion. In olden days, most orthodontic appliances were made up of metals, but they are highly corrosive. Later, they were replaced by noble metals and their alloys (gold, platinum, silver alloys), which are corrosion resistant, but the lack of tensile strength and flexibility made them inappropriate for complex machining and joining when used as traction bars. In 1932, stainless steel was introduced and has been main stay material in orthodontics till now with a wide range of applications in both fixed and removable appliance, as the force per unite activation with stainless steel was greater than gold.

Several studies have investigated whether orthodontic appliances release metallic ions, through emission of electro-galvanic current, with saliva as the medium or through continuous erosion over time. ${ }^{1}$

Nickel is the most common cause of metal-induced allergic content dermatitis in human beings and produces more allergic reaction than all other metals combined. ${ }^{1}$ Second in frequency is chromium. Nickel was discovered by Axel Fredrik Cronstedt in Sweden in 1751; it is from the German word "Kupernickel," meaning devils copper or St Nicholas copper. 
The most significant human exposure to nickel and chromium occurs through the diet. The average dietary intake for nickel is 100 to $300 \mu \mathrm{g} /$ day, and for chromium is 50 to $200 \mu \mathrm{g} /$ day. Hensten-Pettersen and Jacobsen and Sunderman showed that the amount of nickel in human saliva ranges from 0.8 to $4.5 \mu \mathrm{g} / 1$. The estimated lethal dose for nickel and chromium in human is about 50 and $500 \mathrm{mg} / \mathrm{kg}$ and 50 to $70 \mathrm{mg} / \mathrm{kg}$ body weight respectively.

Nickel allergies are estimated to be $16.9 \%$ of males and $23.8 \%$. Chromium allergy is estimated at $10 \%$ in males and $3 \%$ in females. ${ }^{2}$

\section{AIMS AND OBJECTIVES}

The aim of this study was to evaluate the release of nickel and chromium ions in human saliva during fixed orthodontic therapy.

Metallic ions assessed were

- Nickel

- Chromium

Mode of assessment

- Human saliva

Variables assessed

- Saliva sample before orthodontic treatment

- Saliva sample after 10 days of bonding

- Saliva sample after 1 month of bonding

\section{MATERIALS AND METHODS}

The study was carried out with 10 patients who required fixed orthodontic treatment. They were selected based on the following criteria.

\section{Inclusion Criteria}

- Patients in the age range of 14 to 23 years.

- Class I bimaxillary cases
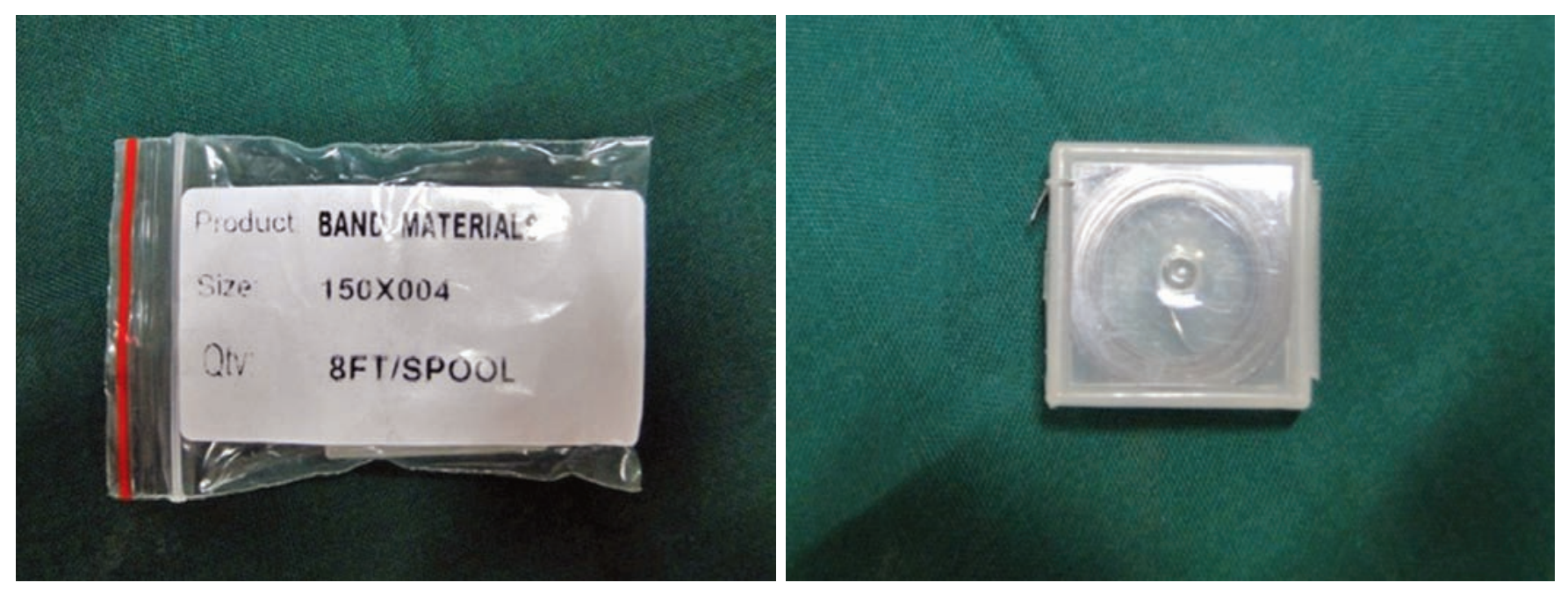

Fig. 2: Bands: Custom-made bands with welded ortho organizer tubes upper triple tube lower double tube 0.022
- Patient required all four premolar extractions

- Second molars were not included

\section{Exclusion Criteria}

- Patients with metallic restorations

- Patients with any metal crowns

- Patients with autoimmune disorder

Ten patients with Angle's Class-I malocclusion with bimaxillary protrusion without any metal restorations or crowns and with all the permanent teeth were selected.

Five male patients and five female patients in the age group range of 14 to 23 years were scheduled for orthodontic treatment with first premolar extraction. The entire procedure was explained to the patient and a written consent was taken.

\section{Armamentarium}

The following materials were used as listed below from Figures 1 to 8 with the corresponding pictures.

The first sample was collected before extraction at the first visit after planning the treatment. Then, the patients were sent for extraction of all first premolars. Banding and bonding were performed on the same day.

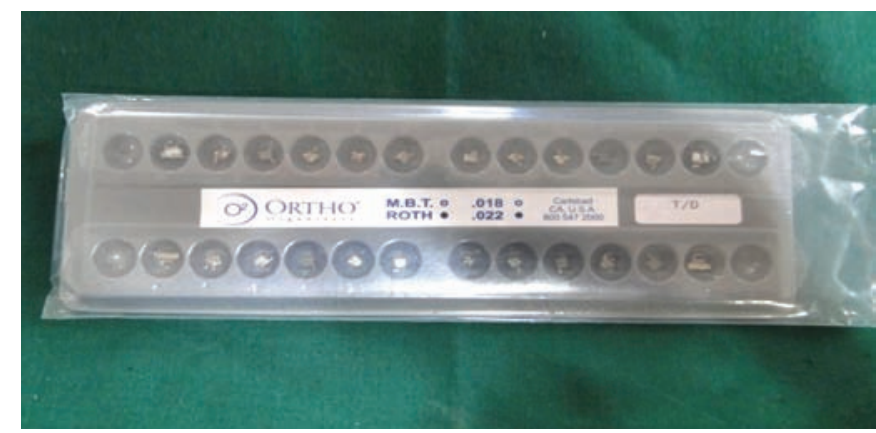

Fig. 1: Brackets: Stainless steel ortho organizer 0.022 slot MBT brackets 

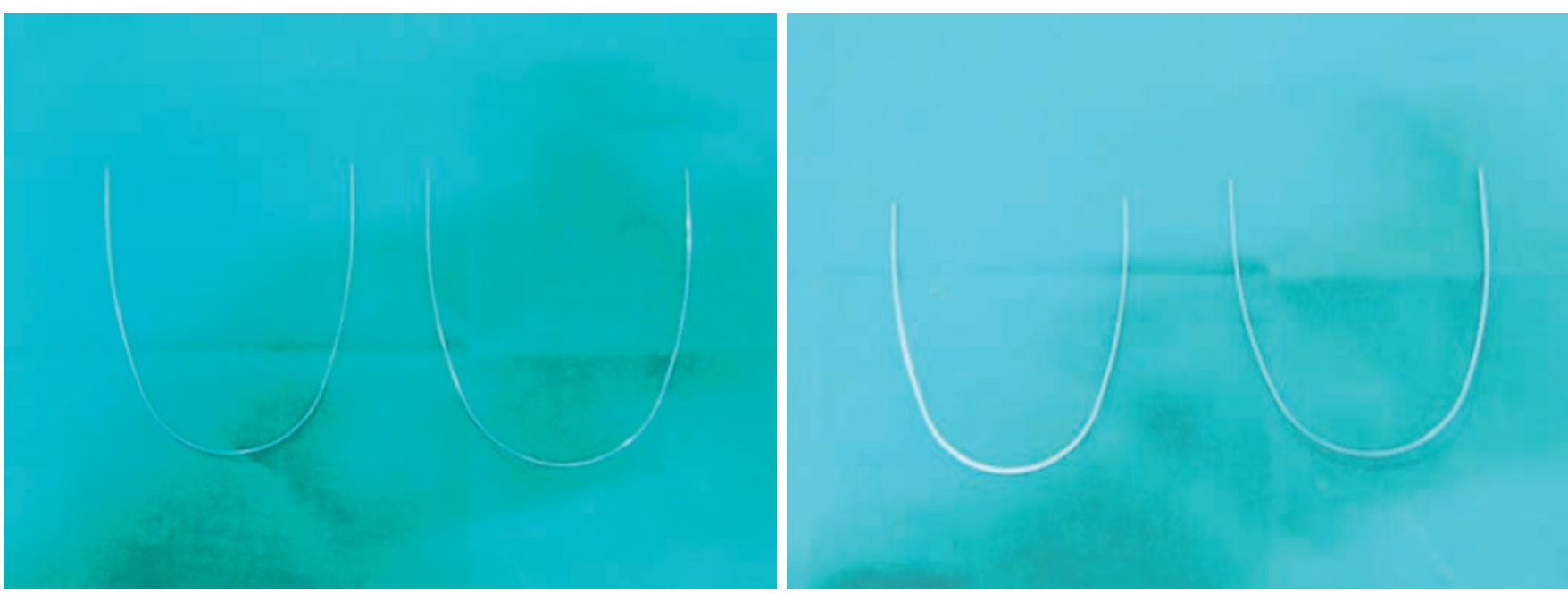

Fig. 3: Archwires: (3M)

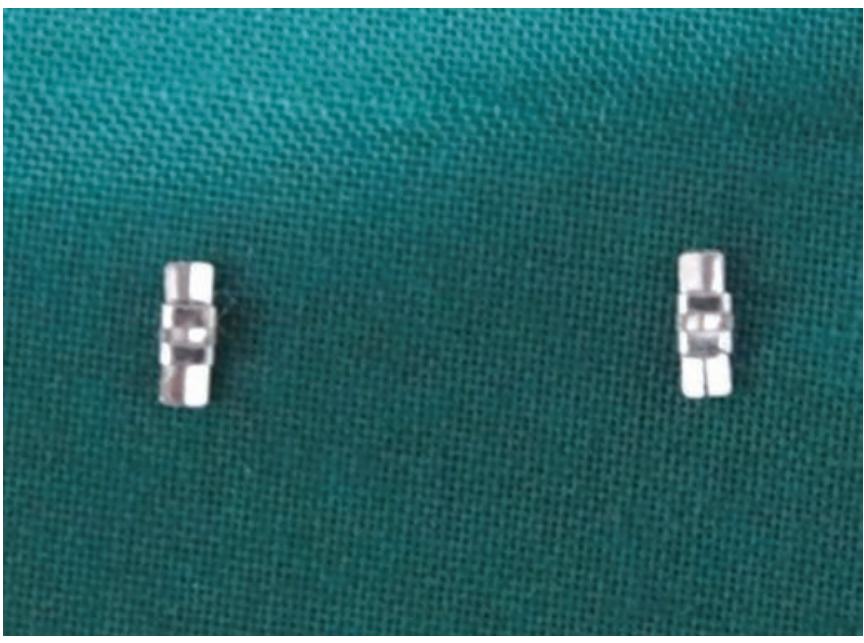

Fig. 4: Attachments: Lingual sheaths Ormco (upper first molars)

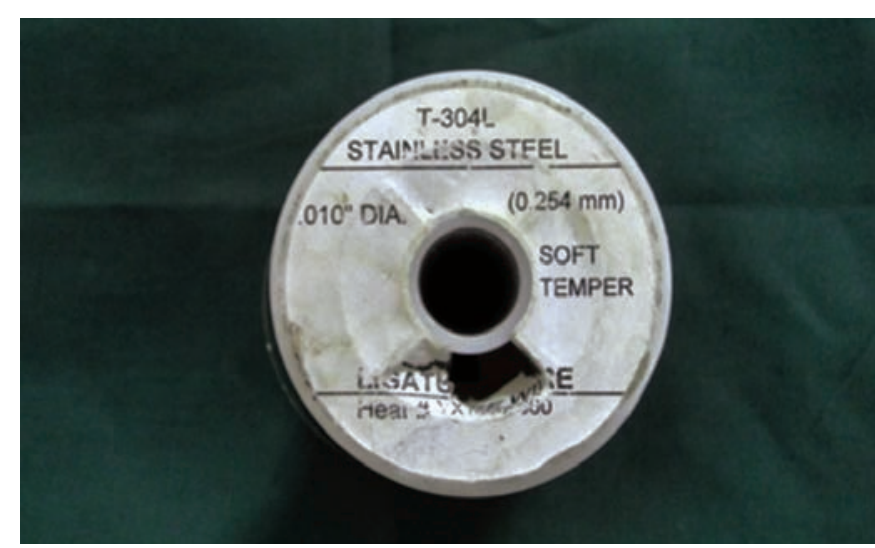

Fig. 6: 0.010-inch ligature wire

Second molar banding was not done for all the patients. Custom-fabricated bands were made for all the first molars and welded with ortho organizer buccal tubes. The upper bands had an attachment (lingual sheaths). The bands were cemented with glass ionomer cement. Then, the bonding procedure was carried out with normal

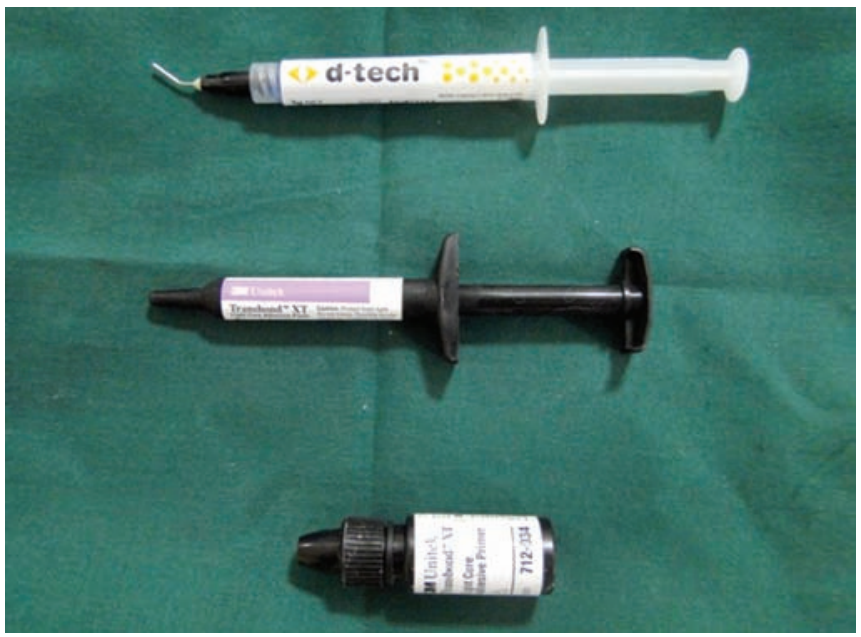

Fig. 5: Bonding adhesive: 3M Unitek Transbond-XT

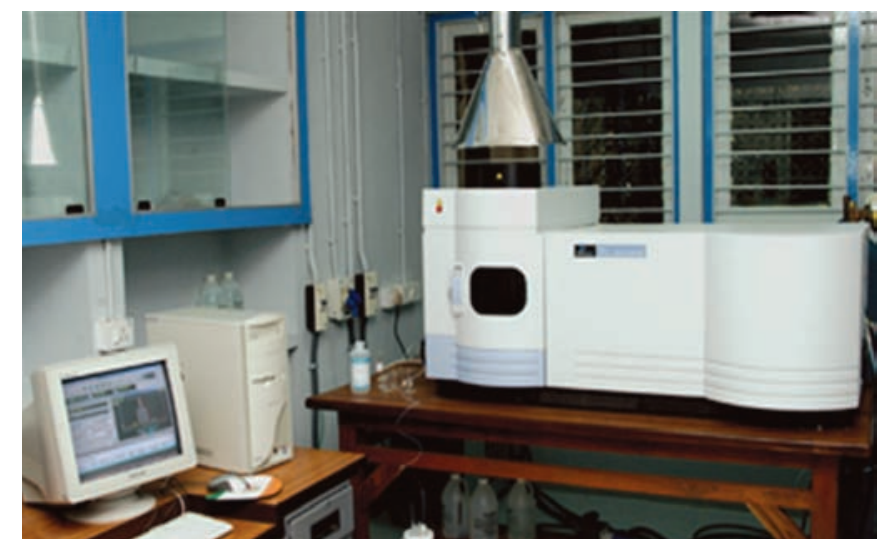

Fig. 7: Analytical device: Inductively coupled plasma optical emission spectrometry (PerkinElmar-optima 5200)

etching procedure and using Transbond-XT adhesive. All 16 brackets were bonded. Canine lace backs were given with 0.010-inch ligature and $0.016 \mathrm{NiTi}$ wire was placed. The patient was called back after 10 days and the saliva sample was collected. The patient was called after 30 days from the day of bonding. The same procedure 


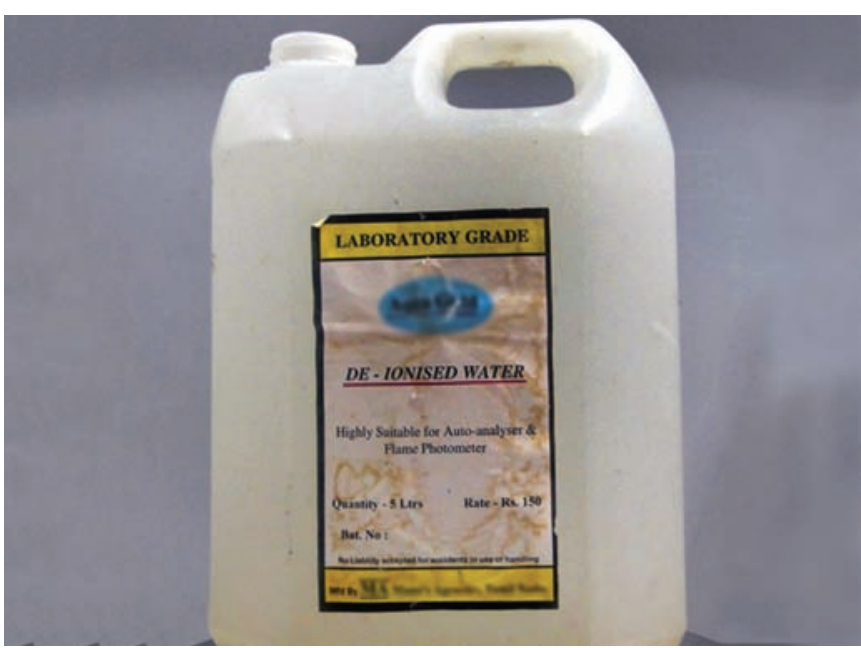

Fig. 8: Deionized water

was carried out and the saliva samples were collected and stored.

\section{Method of Collection of Sample}

The patients were made to sit in the dental chair in an upright position and $5 \mathrm{ml}$ of deionized water was measured and given to the patient to gargle for 1 minute. Then, the samples were collected using a 5-ml syringe, transferred to a plastic container, and then stored. After collection, the samples were stored in a cool place.

\section{Analytical Procedure}

The supernatant solution was separated. (The collected samples were kept undisturbed for a period of time to separate the larger particles). The lower one-third of the sediment sample was discarded. Before testing the samples, the blank deionized water (which was given to the patients to gargle) was tested to calibrate the device. These samples were then analyzed with inductively coupled plasma optical emission spectrometry (ICP-OES) PerkinElmar-Obtima 5200 in sophisticated analytical instrumentation facility at IIT Madras (two-way repeated measures analysis of variance by ranks). Standard detectable limit below Cr: $0.007 \mathrm{mg} / \mathrm{l}$; Ni: $0.015 \mathrm{mg} / \mathrm{l}$; the collected samples were then analyzed for nickel and chromium levels in stainless steel. ${ }^{3}$

Metal content in digested saliva samples was determined by inductively coupled plasma optical emission spectrometry. Instrumental performance optimization, including gas flow rate, ions lens voltage torch alignment, was carried out according to manufacturer instructions (Perkin-Elmer-Sciex, Elan version 3.0, Software).

\section{Statistical Analysis}

The data obtained were entered in microsoft (MS) Excel spreadsheet and statistical analysis was performed. Statistical Package for the Social Sciences (SPSS) software was used for analysis. The p-value was set at $<0.005$ and paired $t$ test was performed.

\section{RESULTS}

Ten patients were included in the study. The samples were grouped based on the day of collection of saliva. Control group sample was collected before the day of bonding of metal brackets (control group). After the 10th day of strap up, samples were collected from all the patients (group 1) similarly after 1 month (group 2). The levels of nickel chromium were assessed in inductively coupled plasma optical emission spectrometry (ICP-OES). The data were tabulated and statistically analyzed (Tables 1 to 7).

Table 1: Levels of nickel and chromium

\begin{tabular}{|c|c|c|c|c|c|c|}
\hline & \multicolumn{2}{|c|}{ Control group } & \multicolumn{2}{|c|}{ Group 1 (10th-day sample) } & \multicolumn{2}{|c|}{ Group 2 (30th-day sample) } \\
\hline & Nickel & Chromium & Nickel & Chromium & Nickel & Chromium \\
\hline 1 & $0.003 \mathrm{mg} / \mathrm{l}$ & $0.002 \mathrm{mg} / \mathrm{l}$ & $0.036 \mathrm{mg} / \mathrm{l}$ & $0.002 \mathrm{mg} / \mathrm{l}$ & $0.040 \mathrm{mg} / \mathrm{l}$ & $0.008 \mathrm{mg} / \mathrm{l}$ \\
\hline 2 & $0.005 \mathrm{mg} / \mathrm{l}$ & $0.002 \mathrm{mg} / \mathrm{l}$ & $0.035 \mathrm{mg} / \mathrm{l}$ & $0.002 \mathrm{mg} / \mathrm{l}$ & $0.038 \mathrm{mg} / \mathrm{l}$ & $0.016 \mathrm{mg} / \mathrm{l}$ \\
\hline 3 & 0.004 mg/l & $0.001 \mathrm{mg} / \mathrm{l}$ & $0.014 \mathrm{mg} / \mathrm{l}$ & $0.003 \mathrm{mg} / \mathrm{l}$ & $0.045 \mathrm{mg} / \mathrm{l}$ & $0.013 \mathrm{mg} / \mathrm{l}$ \\
\hline 4 & $0.003 \mathrm{mg} / \mathrm{l}$ & $0.002 \mathrm{mg} / \mathrm{l}$ & $0.036 \mathrm{mg} / \mathrm{l}$ & $0.002 \mathrm{mg} / \mathrm{l}$ & $0.026 \mathrm{mg} / \mathrm{l}$ & $0.010 \mathrm{mg} / \mathrm{l}$ \\
\hline 5 & 0.004 mg/l & $0.003 \mathrm{mg} / \mathrm{l}$ & $0.022 \mathrm{mg} / \mathrm{l}$ & $0.002 \mathrm{mg} / \mathrm{l}$ & $0.036 \mathrm{mg} / \mathrm{l}$ & $0.007 \mathrm{mg} / \mathrm{l}$ \\
\hline 6 & $0.006 \mathrm{mg} / \mathrm{l}$ & $0.002 \mathrm{mg} / \mathrm{l}$ & $0.011 \mathrm{mg} / \mathrm{l}$ & $0.002 \mathrm{mg} / \mathrm{l}$ & $0.038 \mathrm{mg} / \mathrm{l}$ & $0.009 \mathrm{mg} / \mathrm{l}$ \\
\hline 7 & $0.004 \mathrm{mg} / \mathrm{l}$ & $0.003 \mathrm{mg} / \mathrm{l}$ & $0.016 \mathrm{mg} / \mathrm{l}$ & $0.006 \mathrm{mg} / \mathrm{l}$ & $0.034 \mathrm{mg} / \mathrm{l}$ & $0.009 \mathrm{mg} / \mathrm{l}$ \\
\hline 8 & $0.002 \mathrm{mg} / \mathrm{l}$ & $0.003 \mathrm{mg} / \mathrm{l}$ & $0.036 \mathrm{mg} / \mathrm{l}$ & $0.006 \mathrm{mg} / \mathrm{l}$ & $0.036 \mathrm{mg} / \mathrm{l}$ & $0.012 \mathrm{mg} / \mathrm{l}$ \\
\hline 9 & $0.005 \mathrm{mg} / \mathrm{l}$ & $0.003 \mathrm{mg} / \mathrm{l}$ & $0.050 \mathrm{mg} / \mathrm{l}$ & $0.007 \mathrm{mg} / \mathrm{l}$ & $0.036 \mathrm{mg} / \mathrm{l}$ & $0.015 \mathrm{mg} / \mathrm{l}$ \\
\hline 10 & 0.003 mg/l & $0.003 \mathrm{mg} / \mathrm{l}$ & $0.032 \mathrm{mg} / \mathrm{l}$ & $0.005 \mathrm{mg} / \mathrm{l}$ & $0.041 \mathrm{mg} / \mathrm{l}$ & $0.004 \mathrm{mg} / \mathrm{l}$ \\
\hline
\end{tabular}

Table 2: Paired samples t test to compare mean values between baseline and 10th day

\begin{tabular}{lllllll}
\hline Pair & Variable & $n$ & Mean & Std. dev & $t$ value & $p$-value \\
\hline Pair & Nickel - Base line & 10 & 0.0039 & 0.0012 & 6.114 & $<0.001$ \\
1 & Nickel - 10th day & 10 & 0.0288 & 0.0125 & & \\
\hline
\end{tabular}

Table 3: Nickel comparison between baseline and 30th day

\begin{tabular}{lllllll}
\hline Pair & Variable & $n$ & Mean & Std. dev & $t$ & $p$-value \\
\hline Pair & Nickel - Baseline & 10 & 0.0039 & 0.0012 & 21.128 & $<0.001$ \\
1 & Nickel - 30th day & 10 & 0.0370 & 0.0050 & &
\end{tabular}


Leaching of Nickel and Chromium Ions

Table 4: Nickel comparison between 10th day and 30th day

\begin{tabular}{lllllll}
\hline Pair & Variable & $n$ & Mean & Std. dev & $t$ & $p$-value \\
\hline Pair 1 & Nickel - 10th day & 10 & 0.0288 & 0.0125 & 1.766 & 0.111 \\
& Nickel - 30th day & 10 & 0.0370 & 0.0050 & & \\
\hline
\end{tabular}

Table 6: Levels of chromium between baseline and 30th day

\begin{tabular}{lllllll}
\hline Pair & Variable & $n$ & Mean & Std. dev & $t$ & $p$-value \\
\hline Pair 1 & $\begin{array}{l}\text { Chromium - } \\
\text { Baseline } \\
\text { Chromium - }\end{array}$ & 10 & 0.0024 & 0.0007 & 6.269 & $<0.001$ \\
& 30th day & 0.0103 & 0.0037 & & \\
\hline
\end{tabular}

\section{STATISTICAL ANALYSIS}

Kolmogorov-Smirnov test and Shapiro-Wilks test results show that the variables follow normal distribution. Therefore, to analyze the data, parametric tests are applied. To compare mean values between time points, paired $\mathrm{t}$ test was applied. The $\mathrm{p}$-value was set at $<0.005$.

When comparing Ni levels at baseline and 10th the results were statistically significant. There was a significant rise in nickel levels in saliva.

Nickels release was even more even on 30th day than the baseline values, which was statistically significant.

There was no significant difference in 10th and 30thday nickel release, though there was a numerical increase but no statistical significance (Graph 1).

When comparing the results between baseline and 10thday chromium levels, there was no statistical significance.

The level of chromium was significantly more on 30th day than baseline.

Chromium levels were more in 30th-day sample than 10th day; this was statistically significant (Graph 2).

\section{DISCUSSION}

Toxic effect from orthodontic appliances rarely occurs. Small quantities of metal ions can cause allergic reactions

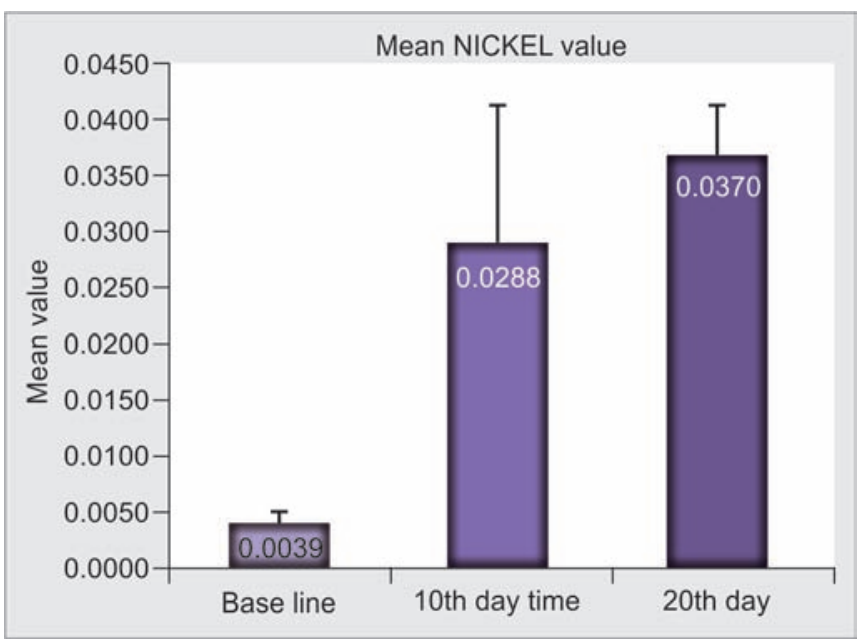

Graph 1: Mean nickel values
Table 5: Levels of chromium between baseline and 10th day

\begin{tabular}{lllllll}
\hline Pair & Variable & $n$ & Mean & Std. dev & $t$ & $p$-value \\
\hline Pair 1 & $\begin{array}{l}\text { Chromium - } \\
\text { Baseline } \\
\text { Chromium - }\end{array}$ & 10 & 0.0024 & 0.0007 & 2.414 & 0039 \\
& 10 & 0.0037 & 0.0021 & & \\
10th day & & & & & \\
\hline
\end{tabular}

Table 7: Levels of chromium between 10th day and 30th day

\begin{tabular}{lllllll}
\hline Pair & Variable & $n$ & Mean & Std. dev & $t$ & $p$-value \\
\hline Pair & Chromium - 10th day & 10 & 0.0037 & 0.0021 & 5.211 & 0.001 \\
1 & Chromium - 30th day & 10 & 0.0103 & 0.0037 & &
\end{tabular}

because fixed orthodontic appliance is used more than 2 to 3 years in oral cavity. Scientists observed large variation in the chromium and nickel concentrations in saliva ${ }^{4}$; ingested amount of chromium or nickel released from orthodontic appliances is less than the daily dietary intake levels. Corrosion of orthodontic appliances and their subsequent metal ion release in oral environment is governed by two factors: first, manufacturing process including the type of alloy and the characteristics of the metals used ${ }^{5}$ and second, environmental factors, such as mechanical stress, diet, time of the day, salivary flow rate, and health and psychosomatic condition of the individual. When measuring the nickel release from various stainless steel materials, sweat, blood, and urine, it was observed that the surface finish of the materials significantly affected the nickel release. From polished materials, nickel release into each of the test fluids was low. A number of studies have been carried out on the biocompatibility of orthodontic materials, with the aim of determining a limit of biological tolerance and assessing whether the ions released from such materials are within these limits.

Singh et $\mathrm{ll}^{6}$ studied the level of $\mathrm{Ni}$ and $\mathrm{Cr}$ in the saliva of 10 patients with fixed orthodontic appliances from the beginning of their treatment. The highest level was found

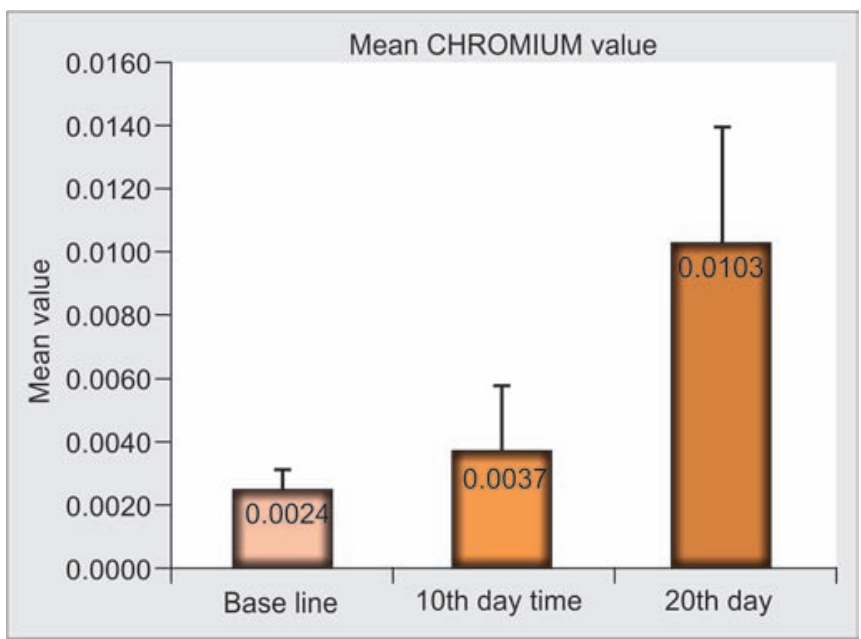

Graph 2: Mean chromium values 
1 week after appliance placement. Kerousou et $\mathrm{al}^{7}$ found that during the 1st month of treatment, fixed orthodontic appliances did not significantly affect $\mathrm{Ni}$ and $\mathrm{Cr}$ concentrations in saliva. The release rates of $\mathrm{Ni}$ and $\mathrm{Cr}$ from stainless steel and NiTi arch wires were not significantly different. Previous studies have examined Ni release from different arch wires and have concluded that the maximum amount of $\mathrm{Ni}$ released from all tested arch wires was 700 times lower than the concentrations necessary to elicit cytotoxic reactions in humans ${ }^{8}$ The release of $\mathrm{Ni}$ from fixed orthodontic appliances was reported to be related to the composition and manufacturing method of the orthodontic appliance, but not to the Ni content. ${ }^{9,10}$ Urinary excretion levels of $\mathrm{Ni}$ in orthodontic patients were studied, ${ }^{11}$ who found that Ni levels were significantly increased 2 months after appliance placement.

This study investigates the release of metal ions from fixed orthodontic appliance. Fixed orthodontic appliances, which contain variable amounts of $\mathrm{Ni}$ and $\mathrm{Cr}$, can leach these metals into the saliva, which may lead to an immune response. However, previous studies have not explored the amount of $\mathrm{Ni}$ and $\mathrm{Cr}$ leached into saliva over an extended period of time. The main advantage of the present in vivo study is that the concentrations of salivary metals ions were recorded in the natural oral environment of the patient where actual adverse effects of increased metal concentrations take place. So, this study was carried out to investigate the metal ion concentrations in the saliva of the patient wearing fixed orthodontic appliances (20 brackets, eight bands and wires) and found the greatest release of ions during the first 10 days and a gradual decline thereafter. This kinetics of ion release coincides with results from other studies and can be explained by an initial surge of ion release from the metal surface or by formation of a stable oxide layer that slows down further ion release. While comparing levels of nickel in saliva, there was a significant rise from baseline to 10th and 30th-day sample, which was statistically significant. While comparing 10th day with that of 30th day, there was no statistical significance. The levels of chromium ion in the saliva were more on 30th day sample while comparing with the 10th day sample.

\section{CONCLUSION}

- The current study showed the greatest release of ions during the first 10 days and a gradual decline thereafter.
- Control group had traces of nickel and chromium.

- While comparing levels of nickel in saliva, there was a significant rise from baseline to 10th and 30th-day sample, which was statistically significant.

- While comparing 10th day with that of 30th day, there was no statistical significance.

- The levels of chromium ion in the saliva were more on 30th day and when comparing 10th-day sample to 30th day, there was statistical significance.

\section{REFERENCES}

1. Sfondrini MF, Cacciafesta V, Maffia E, Scribante A, Alberti G, Biesuz R, Klersy C. Nickel release from new conventional stainless steel, recycled, and nickel-free orthodontic brackets: An in vitro study. Am J Orthod Dentofacial Orthop 2010 Jun;137(6):809-815.

2. Hwang CJ, Shin JS, Cha JY. Metal release from simulated fixed orthodontic appliances. Am J Orthod Dentofacial Orthop 2001 Oct;120(4):383-391.

3. Marigo M, Nouer DF, Genelhu MC, Malaquias LC, Pizziolo VR, Costa AS, Martins-Filho OA, Alves-Oliveira LF. Evaluation of immunologic profile in patients with nickel sensitivity due to use of fixed orthodontic appliances. Am J Orthod Dentofacial Orthop 2003 Jul;124(1):46-52.

4. Eliades T, Trapalis C, Eliades G, Katsavrias E. Salivary metal levels of orthodontic patients: a novel methodological and analytical approach. Eur J Orthod 2003 Feb;25(1): 103-106.

5. Matasa CG. Attachment corrosion and its testing. J Clin Orthod 1995 Jan;29(1):16-23.

6. Singh DP, Sehgal V, Pradhan KL, Chandna A, Gupta R. Estimation of nickel and chromium in saliva of patients with fixed orthodontic appliances. World J Orthod 2008 Fall;9(3):196-202.

7. Kerousuo H, Kullaa A, Kerousuo E, Kanerva L, HenstenPettersen A. Nickel allergy in adolescents in relation to orthodontic treatment and piercing of ears. Am J Orthod Dentofacial Orthop 1996 Feb;109(2):148-154.

8. Jia W, Beatty MW, Reinhardt RA, Petro TM, Cohen DM, Maza CR, Strom EA, Hoffman M. Nickel release from orthodontic arch wires and cellular immune response to various nickel concentrations. J Biomed Mater Res 1999;48(4): 488-495.

9. Grimsdottir MR, Gjerdet NR, Hensten-Pettersen A. Composition and in vitro corrosion of orthodontic appliances. Am J Orthod Dentofacial Orthop 1992 Jun;101(6):525-532.

10. Kim H, Johnson JW. Corrosion of stainless steel, nickeltitanium, coated nickel-titanium, and titanium orthodontic wires. Angle Orthod 1999 Feb;69(1):39-44.

11. Menezes L, Quintao C, Bolognese A. Urinary excretion level of nickel in orthodontic patients. Am J Orthod Dentofacial Orthop 2007;131(5):635-638. 